\title{
Synchronous bilateral epithelial-myoepithelial carcinoma of the parotid gland: case report and review of the literature
}

\author{
J. van Tongeren $\cdot$ D. H. K. V. Creytens • \\ E. V. Meulemans $\cdot$ R. B. J. de Bondt $\cdot$ J. de Jong $\cdot$ \\ J. J. Manni
}

Received: 30 May 2008 / Accepted: 20 September 2008 / Published online: 8 October 2008

(c) The Author(s) 2008. This article is published with open access at Springerlink.com

\begin{abstract}
Synchronous bilateral malignancy in the parotid glands is extremely rare. The English literature reveals nine case reports. The most common synchronous bilateral malignancies are acinic cell carcinoma. Epithelialmyoepithelial carcinoma is an uncommon neoplasm comprising $1 \%$ of all salivary gland tumours. In this case report, we describe, to our best of knowledge, the first case of a patient with a synchronous bilateral epithelial-myoepithelial carcinoma of the parotid gland. The clinical histopathological and immunohistochemical peculiarities are elucidated. Imaging studies like ultrasonography are mandatory for both parotid glands and upper necks in the clinical presence of a unilateral parotid gland tumour.
\end{abstract}

Keywords Parotid gland · Epithelial-myoepithelial carcinoma $\cdot$ Bilateral $\cdot$ Synchronous

J. van Tongeren $(\bowtie)$

Department of Otorhinolaryngology, Academic Medical Center,

Meibergdreef 9, 1105 AZ Amsterdam, The Netherlands

e-mail: j.vtongeren@amc.uva.nl

D. H. K. V. Creytens · E. V. Meulemans

Department of Pathology, University Hospital Maastricht,

Maastricht, The Netherlands

R. B. J. de Bondt

Department of Radiology, University Hospital Maastricht,

Maastricht, The Netherlands

J. de Jong

Department of Radiotherapy, University Hospital Maastricht, Maastricht, The Netherlands

\section{J. J. Manni}

Department of Otorhinolaryngology/Head and Neck Surgery, University Hospital Maastricht, Maastricht, The Netherlands

\section{Introduction}

Multiple primary tumours of the parotid gland may occur unilaterally, bilaterally, or less commonly, the combination of bilateral primary parotid gland tumour with unilateral multifocal parotid gland tumours. The tumours may show identical or different histology and may present synchronously or metachronously [1]. The occurrence of these multiple primary parotid gland tumours is low and is reported between 1.7 and $5 \%$ of all parotid gland tumours [2-4].

Incidences of bilateral parotid gland tumours are even lower and occur between 1.3 and 3.5\% [2-5]. Warthin tumour is the most common bilateral parotid gland tumour and accounts for about $85 \%$ of all cases [2, 4].

Malignant bilateral primary parotid gland tumours are rare. Synchronous bilateral parotid gland tumours are extremely rare. Nine cases were found at literature search in the databases Pubmed and Medline using the following Mesh headings: Parotid Neoplasms and Neoplasms, Multiple Primary. The majority of cases are acinic cell carcinoma (Table 1). To the best of our knowledge, we report the first patient with a synchronous bilateral epithelial-myoepithelial carcinoma of the parotid glands.

\section{Case report}

Clinical course

A 40-year-old male had noticed a slowly growing painless mass in the left pre-auricular area in the past 4 years; there where no additional complaints. Ultrasonography (US) of the left parotid region and neck and computed tomography (CT) of the head and neck revealed a cystic lesion with a diameter of $2 \mathrm{~cm}$ within the left parotid gland; there where 
Table 1 Synchronous bilateral parotid gland carcinoma

\begin{tabular}{lcll}
\hline Author & Age & Sex & Histology \\
\hline Bauer and Bauer (1953) [6] & 65 & M & Acinic cell carcinoma \\
Diamant et al. (1961) [7] & 71 & M & Acinic cell carcinoma \\
& 55 & M & Acinic cell carcinoma \\
Clarke et al. (1969) [8] & 57 & F & Acinic cell carcinoma \\
Levin et al. (1975) [9] & 57 & F & Acinic cell carcinoma \\
Delides et al. (2005) [10] & 64 & M & Acinic cell carcinoma \\
Berkeley (1959) [11] & 5 & M & Adenocarcinoma \\
Ferlito (1978) [12] & 67 & M & Adenocarcimoma \\
Hakuba et al. (2003) [13] & 48 & M & Mucoepidermoid carcinoma \\
van Tongeren et al. (2008) [This study] & 40 & M & Epithelial-myoepithelial carcinoma \\
\hline
\end{tabular}

no enlarged or pathologic lymph nodes. The tumour was excised via a superficial parotidectomy approach in a regional hospital. The histology showed an epithelial-myoepithelial carcinoma with extension in the resection margins. The patient was referred to the University Hospital Maastricht for postoperative radiotherapy. The past medical history revealed asthma and excision of a pleomorphic adenoma in the left parotid gland 12 years before.

On clinical examination at the Multidisciplinary Head and Neck Outpatient Clinic, the left parotid region showed a pre- and infra-auricular scar, concordant with a standard approach for parotidectomy. There was mild impairment of function of the marginal branch of the facial nerve and hypoaesthesia of the skin in the parotid area and auricle, supplied by branches of the greater auricular nerve. The right parotid gland showed no palpable abnormalities. The multidisciplinary work-up before the initial planned postoperative radiotherapy included a routine US study of the parotid regions and entire neck, which revealed in the right parotid gland two nodular lesions: posterior deep of $0.4 \mathrm{~cm}$ and anterior superficial of 0.7 x $0.4 \mathrm{~cm}$ diameter, respectively. There was no additional pathology in the neck. US-guided fine-needle aspiration cytology of the two lesions within the right parotid gland revealed a malignant lesion, probably a muco-epidermoid carcinoma, situated posterior deep in the parotid gland. The other anterior superficial lesion revealed no malignancy.

MRI demonstrated exclusively postoperative effects in the left parotid region. However, the two nodular lesions in the right parotid gland were confirmed (Fig. 1). PET-CT imaging showed a slightly higher signal in the mediastinum, but this was not considered suspect for metastasis. Full blood count, liver and kidney function tests, electrolytes and chest X-ray were all normal.

The Head and Neck Tumour Board advised to perform a bilateral radical parotidectomy with selective neck dissection of Levels II and III with frozen section evaluation eventually followed by extension to a modified radical neck dissection in the presence of metastasis, followed by bilateral postoperative radiotherapy. The patient and his wife were carefully counselled and consent for the proposed treatment was obtained. The total parotidectomy on the right side was performed by standard retrograde facial nerve approach, preceded by selective neck dissection of Levels II and III. Frozen section analysis of the neck dissection specimen revealed no metastasis.

At surgical exploration of the left parotid region and neck, it was not possible to identify the facial nerve stem directly due to abundant fibrous scar tissue. Therefore, an ante grade approach by dissection from the peripheral branches was chosen and a total parotidectomy performed with anatomical preservation of facial nerve branches and facial nerve stem. Frozen section analysis of the left selective neck dissection specimen of Levels II and III also revealed no metastasis. Postoperatively, there was only mild neuropraxia on the left side, which recovered completely. The preoperative existing mild dysfunction of the mandibular branch persisted. Based on the histopathological findings of a marginal radical resection of the remaining tumour in the left parotid gland and the radically excised tumour of the right parotid gland, postoperative radiotherapy was indicated for the left side only. This was performed 3 weeks after the last surgery. The schedule was as follows; the parotid region received $70 \mathrm{~Gy}$ and the left side of the neck received $50 \mathrm{~Gy}$, both given in fractions of $2 \mathrm{~Gy}$, five times a week. Psychologic support was given for a 1-year period. Four years postoperative, there are no sings of recurrence. The symptoms of Frey syndrome were successfully treated with Botox injections.

\section{Material and methods}

The surgical specimens were fixed in formalin. Two- to three- $\mu \mathrm{m}$-thick sections for histological examination were routinely processed in paraffin and stained with haematoxylin and eosin. For immuno-histochemical studies, representative sections were evaluated using the avidin-biotin- 

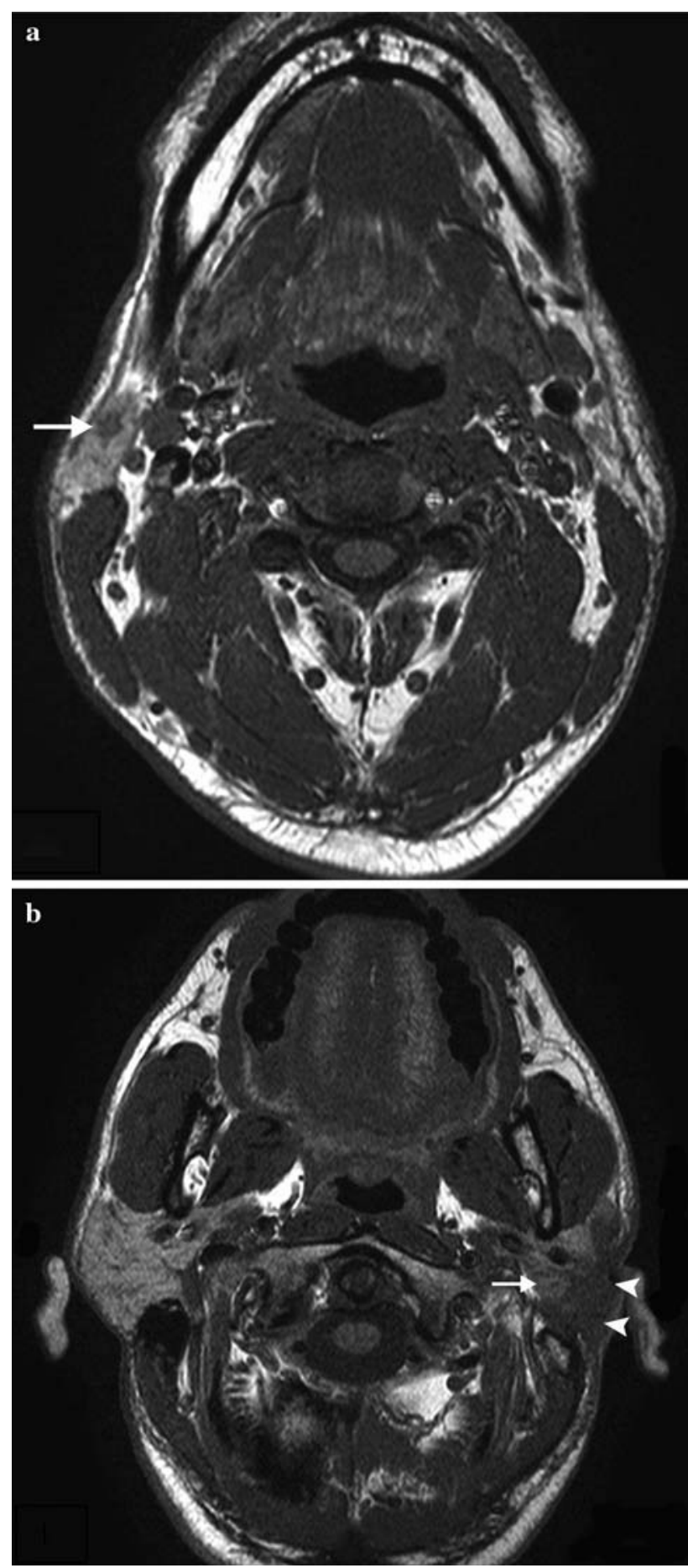

Fig. 1 Axial SE T1-weighted images of the neck showing on the right side (a) in the upper part of the superficial lobe of the parotid gland a small and not well circumscribed lesion (arrow). On the left side (b) in the deep lobe of the parotid gland a hyper-intense region can be appreciated (arrow) besides the hypo-intense postoperative changes in the superficial lobe (arrowheads)

peroxidase complex technique using appropriate positive and negative controls. The immuno-histochemical panel contained antibodies against pankeratin (clone MNF116,
1:500, DAKO), S100 protein (1:5,000, DAKO) and Alfa smooth muscle actin (clone 1A4, 1:1000, Sigma), p63 (Clone 4A4, DAKO).

For mutation analysis in the DNA-binding domain of the p53 gene (exons 5-8), genomic DNA was extracted and analysed by single-strand conformation polymorphism (SSCP). Paraffin-embedded tissue sections $(3 \times 10 \mu \mathrm{m})$ of each tumour were deparaffinised by xylene and dehydrated with $100 \%$ ethanol. DNA was isolated by the DNA Puregene isolation kit (Biozym) and DNA fragments comprising exons 5-8 of the p53 gene were amplified by polymerase chain reaction (PCR) using primers as described previously [14]. A standard PCR reaction in $20 \mu \mathrm{l}$ with a final concentration of $3 \mathrm{mM} \mathrm{MgCl}{ }_{2}$ was performed (35 cycles, annealing temperature $60^{\circ} \mathrm{C}$ ). PCR products were denatured and separated on a nondenaturating $10 \%$ polyacrylamide gel at $40 \mathrm{~W}$ for $3 \mathrm{~h}$ at $12^{\circ} \mathrm{C}$ and analysed by silver staining.

\section{Pathological findings}

The resection of the right parotid gland revealed a relatively well-circumscribed tumour measuring $0.4 \mathrm{~cm}$ in maximum dimension, radically excised with margins more than $0.6 \mathrm{~cm}$. Twenty-two lymph nodes revealed no metastases. In the remaining left parotid gland tissue, a radical-removed tumour of $0.2 \mathrm{~cm}$ in diameter was discovered with a margin of $0.1 \mathrm{~cm}$. Nineteen lymph nodes showed no metastases.

The histological examination of the tumours in the left and right parotid glands showed a similar appearance. The tumours were moderately circumscribed and a thin fibrous connective tissue capsule separates the tumour from the normal parotid gland parenchyma (Fig. 2a). Focally, nests of tumour cells infiltrate the adjacent parotid parenchyma (Fig. 2b). It is composed of ductal elements surrounded by clear cells (Fig. 2c). The epithelial ductal component is arranged in sheets and nests. The ductal cells are flat to cuboidal with a light eosinophilic cytoplasm and a round to oval central placed nucleus. The ductal cells are immunoreactive for pankeratin (MNF 116) (Fig. 2d). The myoepithelial cells are more variable in size than the ductal cells and have variable amounts of clear or light eosinophilic cytoplasm. They are mostly elongated or spindle-shaped. Immunoreactivity for S100 (Fig. 2e) and Alfa smooth muscle actin is intense in the clear myoepithelial cells. Both tumours demonstrate a very strong p63 nuclear staining in the "abluminal" clear myoepithelial cells (Fig. 3). As a positive intern control p63 reactive nuclei were seen in the basal cells of the interlobular ducts and some small-elongated nuclei at the periphery of the acini. The acini as well the luminal cells are negative for $\mathrm{p} 63$. The cytological atypia is mild to moderate (data not shown). The tumours showed a low mitotic rate $\left(1 \mathrm{MF} / 2 \mathrm{~mm}^{2}\right)$ (Fig. 2c). 

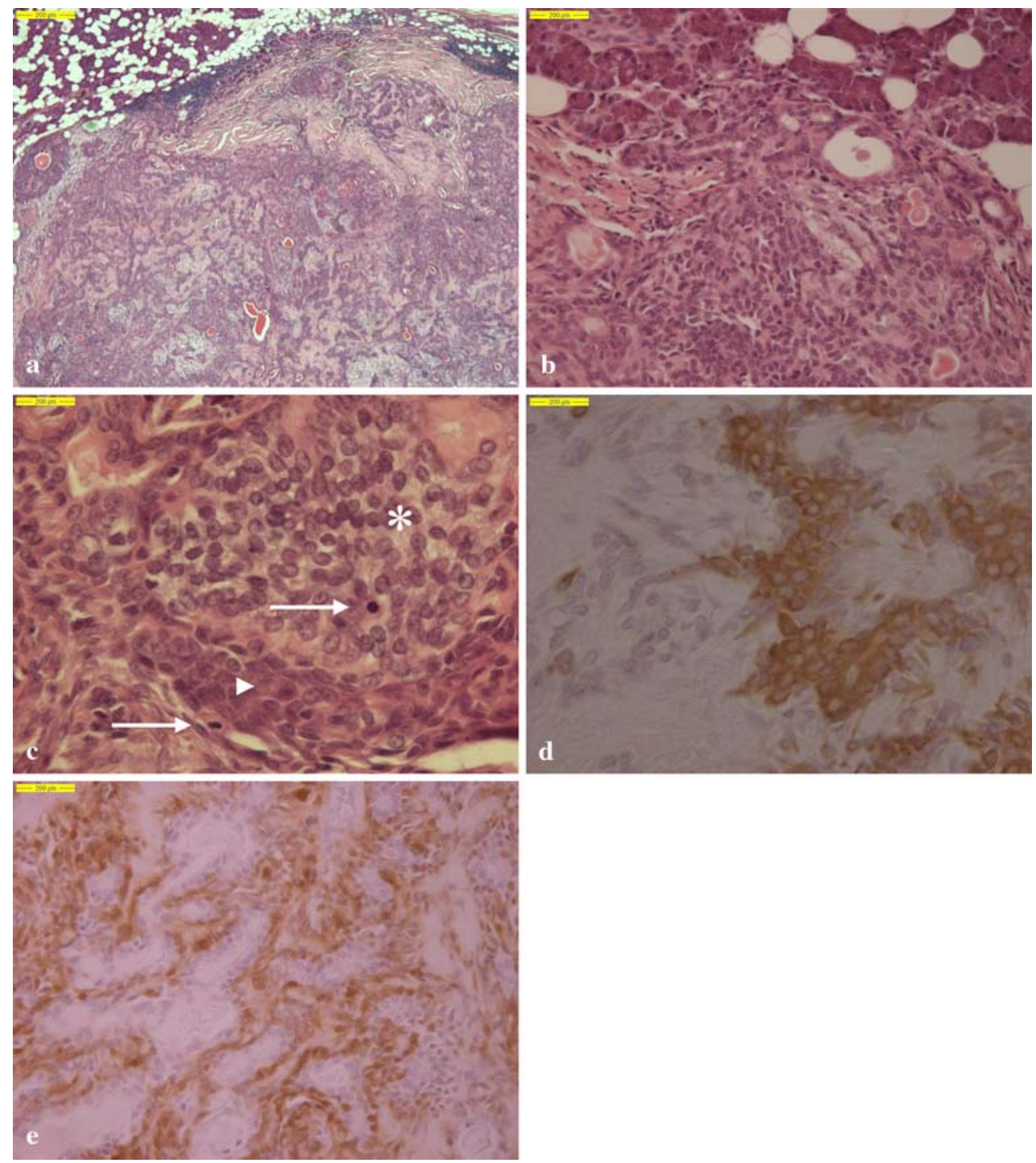

Fig. 2 a Overview of the tumour separated from the normal parotid gland tissue by a thin fibrous pseudo capsule $(\times 2.5, \varnothing 9 \mathrm{~mm})$. b Focally, nests of tumour cells infiltrate the adjacent normal parotid gland $(\times 20, \varnothing 1 \mathrm{~mm})$. c The tumour is composed of ductal epithelial cells (arrowhead) and clear myoepithelial cells (asterisk) (HE $\times 40, \varnothing$

To explain $p 53$ results by molecular events (e.g., gene mutation), tumour specimens were analyzed by singlestrand confirmation polymorphism (SSCP). After extraction of DNA from both samples, the exons were amplified separately. PCR products were separated by SSCP analysis at two temperatures. After silver staining, no mutation in exons $5,6,7$ or 8 of the P53 gene was detected in both tumours.

\section{Discussion}

Synchronous bilateral malignant parotid gland tumours are extremely rare. Until now six cases of acinic cell carcinoma,
$0.5 \mathrm{~mm}$ ); mitotic figures are seen (arrows). d The MNF116 stains strongly the ductal epithelial component $(\times 40, \varnothing 0.5 \mathrm{~mm})$. e The clear myoepithelial cells show strong S100 immunoreactivity $(\times 20, \varnothing$ $1 \mathrm{~mm}$ )

two cases of adenocarcinoma and one case of mucoepidermoid carcinoma have been reported in the English literature. Although Medline and Pubmed are excellent sources of the present literature on this subject, they are known to be incomplete and we may have missed important abstracts or reports. To our best knowledge, this case report is the first description of a synchronous bilateral epithelial-myoepithelial carcinoma of the parotid gland.

Epithelial-myoepithelial carcinoma (EMC) is an uncommon epithelial neoplasm, comprising approximately $1 \%$ of all salivary gland tumours. Therefore, we choose to elaborate into this particular tumour.

The tumour is mainly composed of variable portions of ductal and clear staining myoepithelial cells. EMC is 


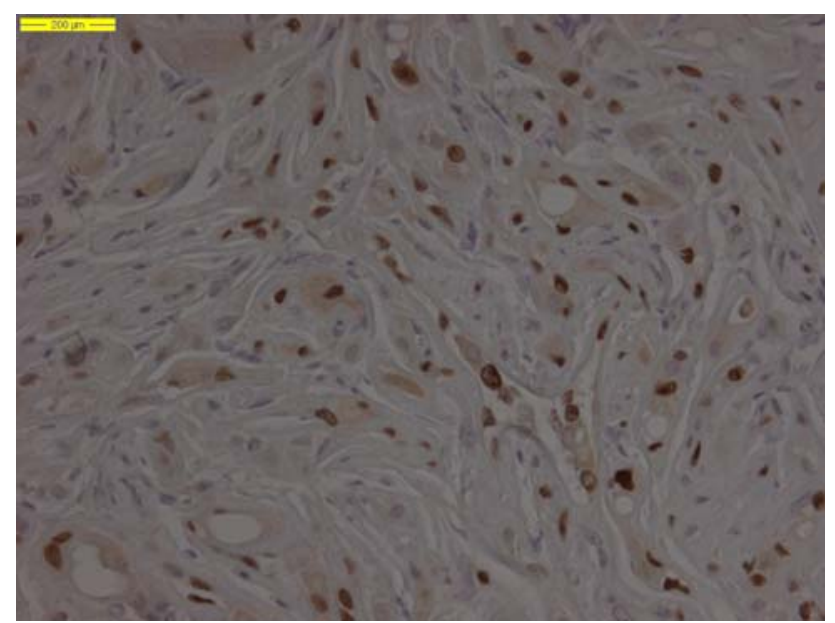

Fig. 3 The myoepithelial component shows also a strong nuclear staining for $\mathrm{p} 63$

predominantly a tumour of the major salivary glands, specially the parotid gland, but they may also arise in minor salivary glands [15-17] and rarely in extra-oral sites such as the paranasal sinuses $[15,16]$, pharynx [16] and bronchus [18]. Tumours with similar histological features to EMC of the salivary gland have been identified in breast and skin $[19,20]$. EMC is primarily a tumour of adults, although tumours in children have been reported [21]. The peak incidence is in the seventh decade of life; the mean age of patients is about 60 years. About $60 \%$ of the patients are female. In 1982, Corio et al. reported the largest series of 16 cases in the English literature [22].

The term epithelial-myoepithelial carcinoma was introduced in 1972 by Donath et al. [23]. This neoplasm was formerly referred to as a clear cell adenoma and adenomyoepithelioma [22, 24].

Because of the tendency to local recurrence and the low metastatic potential, the tumour is now recognised to be a low-grade malignant tumour in the WHO salivary gland classification. In 2001, Deere et al. reported a significant local recurrence rate of $42 \%$ in patients with EMC of the salivary glands [25]. The same authors reported in $10 \%$ of the cases metastases, especially to the periparotid and cervical lymph nodes. Rare EMC might show a very aggressive behaviour with distant metastasis [24, 26]. For many authors, a complete surgical resection is the only and best treatment for EMC. Deere et al. reported that adjuvant radiotherapy might be effective in preventing local recurrence [25].

A typical EMC is histologically composed of a classical double (biphasic) cell lining of smaller inner ductal cells and outer larger clear myoepithelial cells. Immunohistologically, the ductal cells are positive for MNF116 pankeratin and the myoepithelial cells are strongly reactive for the common myoepithelial markers ASMA and S100, but negative for MNF116 pankeratin. The myoepithelial component also shows a strong nuclear staining for $p 63$ (Fig. 2c).

The anti-p63 antibody is a selective immuno-histochemical marker staining the nuclei of basal (progenitor/ stem) cells of stratified epithelium, like skin, the mucosa of the oral cavity, oesophagus, cervix and urothelium [27]. p63 immunoreactivity has been demonstrated in squamous cell and urothelial cells, and is absent in most non-squamous carcinomas [27, 28]. Research has shown that the anti-p63 antibody is a good marker of myoepithelial cells with sensitivity comparable to other myoepithelial markers, like ASMA and calponin, but also with a higher specificity [29]. To date only a few studies on the expression of p63 in salivary gland tumours have been published [27, 29-32]. p63 immuno-histochemistry is only described in two EMCs, also showing a strong nuclear staining of the clear myoepithelial cells [31]. The strong positivity for p63 in our bilateral parotid gland tumour suggests that $p 63$ is up-regulated and that the neoplastic myoepithelium is a key cellular participant in the morphogenesis of EMC. The exact origin of EMC is not clear. Corio et al. considered the EMC to arise from the intercalated ducts [22].

Recently, immunohistochemical positivity for CD117 $[33,34]$ and $\mathrm{Bcl} 2$ [33] was described in EMC. Furuse et al. studied immunohistochemical beta-catenin expression in salivary gland tumours (pleiomorphic adenoma, adenoid cystic carcinoma, polymorphous low-grade adenocarcinoma and EMC) and showed a striking diffuse beta-catenin nuclear positivity in the myoepithelial cell component of the EMC [35].

In the present case report, all histological examinations were similar for both tumours. Surgery is the treatment of choice and to ensure adequate removal, a subtotal or total parotidectomy is recommended, followed by radiotherapy. The fact that, in the left parotid gland, 12 years earlier, a benign tumour was diagnosed and later followed by a malignant tumour makes this case unique. The present report also illustrates that a pre-operative work up of patients with clinically a unilateral parotid gland tumour should include imaging studies like US to exclude occult contra-lateral disease. Post-operative follow-up of patients with a unilateral parotid gland tumour should always include investigation of the contra-lateral parotid gland, as bilateral tumour can occur metachronously.

Conflict of interest statement The authors declare that they have no conflict of interest.

Open Access This article is distributed under the terms of the Creative Commons Attribution Noncommercial License which permits any noncommercial use, distribution, and reproduction in any medium, provided the original author(s) and source are credited. 


\section{References}

1. Seifert G, Donath K (1996) Hybrid tumours of salivary glands. Definition and classification of five rare cases. Eur J Cancer B Oral Oncol 32B:251-259

2. Turnbull AD, Frazell EL (1969) Multiple tumors of the major salivary glands. Am J Surg 118:787-789

3. Ethunandan M, Pratt CA, Morrison A, Anand R, Macpherson DW, Wilson AW (2005) Multiple synchronous and metachronous neoplasms of the parotid gland: the Chichester experience. Br J Oral Maxillofac Surg 44:397-401

4. Yu GY, Ma DQ, Zhang Y, Peng X, Cai ZG, Gao Y, Chen Y (2004) Multiple primary tumours of the parotid gland. Int J Oral Maxillofac Surg 33:531-534

5. Byrne MN, Spector JG (1988) Parotid masses: evaluation, analysis, and current management. Laryngoscope 98:99-105

6. Bauer WH, Bauer JD (1953) Classification of glandular tumors of salivary glands; study of one-hundred forty-three cases. AMA Arch Pathol 55:328-346

7. Diamant H, Eneroth CM, Gejrot T (1961) Bilateral tumors of the parotid gland. J Laryngol Otol 75:699-702

8. Clarke JS, Hentz EC, Mahoney WD (1969) Bilateral acinic cell carcinoma of the parotid gland. Ann Surg 170:866-869

9. Levin JM, Robinson DW, Lin F (1975) Acinic cell carcinoma: collective review, including bilateral cases. Arch Surg 110:64-68

10. Delides A, Velegrakis G, Kontogeorgos G, Karagianni E, Nakas D, Helidonis E (2005) Familial bilateral acinic cell carcinoma of the parotid synchronous with pituitary adenoma: case report. Head Neck 27:825-828

11. Berkeley WT (1959) Nevus sebaceus (Jadassohn) complicated by bilateral salivary gland adenocarcinoma. Plast Reconstr Surg Transplant Bull 23:55-63

12. Ferlito A (1978) Bilateral synchronous trabecular adenocarcinoma of the parotid gland. ORL J Otorhinolaryngol Relat Spec 40:120126

13. Hakuba N, Hyodo M (2003) Synchronous bilateral mucoepidermoid carcinoma of the parotid gland. J Laryngol Otol 117:419421

14. Dai Y, Morishita Y, Mase K, Sato N, Akaogi E, Mitsui T, Noguchi M (2000) Application of the p53 and k-ras gene mutation patterns for cytological diagnosis of recurrent lung carcinomas. Cancer 90:258-263

15. Batsakis JG, el-Naggar AK, Luna MA (1992) Epithelial-myoepithelial carcinoma of salivary glands. Ann Otol Rhinol Laryngol 101:540-542

16. Cho KJ, el-Naggar AK, Ordonez NG, Luna MA, Austin J, Batsakis JG, Epithelial-myoepithelial carcinoma of salivary glands (1995) A clinicopathologic, DNA flow cytometric, and immunohistochemical study of Ki-67 and HER-2/neu oncogene. Am J Clin Pathol 103:432-437

17. Fonseca I, Soares J (1993) Epithelial-myoepithelial carcinoma of the salivary glands. A study of 22 cases. Virchows Arch A Pathol Anat Histopathol 422:389-396

18. Nistal M, Garcia-Viera M, Martinez-Garcia C, Paniagua R (1994) Epithelial-myoepithelial tumor of the bronchus. Am J Surg Pathol $18: 421-425$

19. Murphy GF, Elder DE (1991) Non-melanocytic tumors of the skin. In: Atlas of tumor pathology, 3rd series, Fascicle 1. Armed Forces Institute of Pathology, Washington, DC, pp 83-86
20. Rosen PP, Oberman HA (1993) Tumors of the mammary gland. In: Atlas of tumor pathology, 3rd series, Fascicle 7. Armed Forces Institute of Pathology, Washington, DC, pp 91-96

21. Stafford ND, Wilde A (1997) Parotid cancer. Surg Oncol 6:209213

22. Corio RL, Sciubba JJ, Brannon RB, Batsakis JG (1982) Epithelial-myoepithelial carcinoma of intercalated duct origin. A clinicopathologic and ultrastructural assessment of sixteen cases. Surg Oral Med Oral Pathol 53:280-287

23. Donath K, Seifert G, Schmitz R (1972) Diagnosis and ultrastructure of the tubular carcinoma of salivary gland ducts. Epithelialmyoepithelial carcinoma of the intercalated ducts. Virchows Arch A Pathol Pathol Anat 356:16-31

24. Kumagai M, Suzuki H, Matsuura K, Takahashi E, Hashimoto H, Suzuki H, Tezuka F (2003) Epithelial-myoepithelial carcinoma of the parotid gland. Auris Nasus Larynx 30:201-203

25. Deere H, Hore I, McDermott N, Levin T (2001) Epithelial-myoepithelial carcinoma of the parotid gland: a case report and review of the cytological and histological features. J Laryngol Otol 115:424-426

26. Morinaga S, Hashimoto S, Tezuka F (1992) Epithelial-myoepithelial carcinoma of the parotid gland in a child. Acta Pathol Jpn 42:358-363

27. Edwards PC, Bhuiya T, Kelsch RD (2004) Assessment of p63 expression in the salivary gland neoplasms adenoid cystic carcinoma, polymorphous low-grade adenocarcinoma, and basal cell and canicular adenomas. Oral Surg Oral Med Oral Pathol Oral Radiol Endod 97:613-619

28. Kaufmann O, Fietze E, Mengs J, Dietel M (2001) Value of p63 and cytokeratin $5 / 6$ as immunohistochemical markers for the differential diagnosis of poorly differentiated and undifferentiated carcinomas. Am J Clin Pathol 116:823-830

29. Genelhu MCLS, Gobbi H, Soares FA, Froes de Marques Campos AHJ, Ribeiro CA, Cassali GD (2006) Immunohistochemical expression of p63 in pleiomorphic adenomas and carcinomas expleiomorphic adenomas of salivary glands. Oral Oncol 42:154 160

30. Weber A, Langhanki L, Schütz A, Gerstner A, Bootz F, Wittekind C, Tannapfel A (2002) Expression profiles of p53, p63 and p73 in benign salivary gland tumors. Virchows Arch 441:428-436

31. Bilal H, Handra-Luca A, Bertrand J-C, Fouret PJ (2003) p63 is expressed in basal and myoepithelial cells of human normal and tumor salivary gland tissues. J Histochem Cytochem 51:133-139

32. Emanuel P, Wang B, Wu M, Burstein DA (2005) p63 immuno-histochemistry in the distinction of adenoid cystic carcinoma from basaloid squamous cell carcinoma. Mod Pathol 18:645-650

33. Seethala RR, Barnes EL, Hunt JL (2007) Epithelial-myoepithelial carcinoma a review of the clinicopathologic spectrum and immunophenotypic characteristics in 61 tumors of the salivary glands and upper aerodigestive tract. Am J Surg Pathol 31:44-57

34. Andreadis D, Epivatianos A, Poulopoulos A, Nomikos A, Papazoglou G, Antoniades D, Barbatis C (2006) Detection of C-KIT (CD117) molecule in benign and malignant salivary gland tumours. Oral Oncol 42:57-65

35. Furuse C, Cury PR, Altemani A, dos Santos Pinto D Jr, de Araújo NS, de Araújo VC (2006) Beta-catenin and E-cadherin expression in salivary gland tumors. Int J Surg Pathol 14:212-217 